\title{
Educação inclusiva universitária: o curso de direito
}

University inclusive education: the law course

\author{
Vanessa Vasques Assis dos Reis ${ }^{1}$ \\ Célio Dias Sales² \\ Danilo Nunes ${ }^{3}$
}

\section{Resumo}

O presente trabalho analisa a Educação Inclusiva Universitária sob a perspectiva dos Direitos Humanos, questionando se a Educação Inclusiva vinculada à atenção especializada para pessoas com deficiência seria adequada para alcançar o Objetivo $\mathrm{n}^{\circ} 04$ para o Desenvolvimento Sustentável, proposto pela Organização das Nações Unidas (ONU). Pressupõem-se que a conceituação equivocada quanto à Educação Inclusiva é uma das causas da exclusão ao categorizar e estigmatizar pessoas com deficiência e desconsiderar outros fatores de âmbito econômico e social que obstaculizam o acesso e permanência nas instituições de Ensino Superior. Considerando a diversidade humana, sobretudo quanto às formas de aprendizagem, implementou-se o método de pesquisa-ação para interceder junto aos alunos da primeira turma do curso de Direito, de uma faculdade da Baixada Santista, litoral de São Paulo. O objetivo é verificar e compreender as dificuldades e obstáculos encontrados pelos alunos no

1 Mestre em Direito Internacional com enfoque em Direitos Humanos pela Universidade Católica de Santos ( 2017-2019). Possui graduação em Fonoaudiologia pelo Centro Universitário Lusíada (1995) e graduação em Direito pela Universidade Católica de Santos (2000). Professora Universitária e Pesquisadora na área de Educação, Cidadania e Direitos Humanos. Participa dos Grupos de pesquisas: Praticas Pedagógicas, pesquisa e formação e Regimes e Tutelas Constitucionais, Ambientais e Internacionais, todos pela Universidade Católica de Santos. Membro da Cátedra Sérgio Vieira de Melo da Universidade Católica de Santos

2 Mestre em Direito pela Universidade Metropolitana de Santos (2012). Advogado. Diretor do Núcleo de Reabilitação de Excepcional São Vicente de Paulo - Nurex (gestão 20192022).

3 Doutorando em Administração pela PUC/SP. Mestre em Administração pela Unimonte (2000), área de concentração em Comportamento Organizacional. Professor universitário. 
decorrer do curso e analisar se ações interventivas pautadas na escuta ativa, diálogo e cooperação podem trazer reflexos positivos em relação à aprendizagem destes alunos, servindo de parâmetro para ações inclusivas efetivas no âmbito universitário. Constatou-se a importância de trabalhar o autoconhecimento dos discentes e a formação de docentes livre de padrões pré-estabelecidos de aulas.

Palavras-chave: aprendizagem. educação inclusiva. ensino superior

\section{Abstract}

This paper analyses Inclusive Higher Education from a Human Rights perspective. It questions whether Inclusive Education linked to specialized care for people with disabilities would be efficient to achieve United Nation's Goal 04 for Sustainable Development. The assumption is that the mistaken concept of Inclusive Education is one of the causes for exclusion by categorizing and stigmatizing people with disabilities and disregarding other economic and social factors that hinder access and permanence in Institutions of Higher Education. Considering human diversity and the different forms of learning, this investigation employs the action research method. The aim is to research and propose action alongside first year undergraduate students from the Law course of a Faculty located in Baixada Santista, Brazil. The objective is to verify and understand the difficulties and obstacles encountered by students during the timespan of their undergraduate studies and to analyse if interventional actions based on active listening, dialogue, and cooperation can bring positive reflexes regarding the learning process of these students. Actions herein researched shall serve as a parameter for effective inclusive measures. The research demonstrates the importance of working students' self-knowledge and the training of teachers free from pre-established classroom standards.

Keywords: learning. inclusive education. higher education 


\section{Introdução}

O presente trabalho visa debater a inclusão no ambiente universitário e sua efetiva promoção na concepção de Educação Inclusiva Universitária na perspectiva dos Direitos Humanos. Partindo da análise de um grupo específico, busca refletir sobre as condições necessárias para a implementação de uma Educação Inclusiva em uma faculdade localizada em um dos municípios da Baixada Santista, litoral de São Paulo.

Parte-se da premissa que a Educação Inclusiva deve representar o oferecimento de uma Educação equitativa e de qualidade para todos e todas (ONU, 2015) e considera-se o objetivo número 04 da Agenda 2030 para o Desenvolvimento Sustentável.

Desde março de 2019 vem sendo realizado um estudo com um grupo de estudantes, que atualmente conta com 25 pessoas, com idades entre 20 e 60 anos. São integrantes da primeira turma do curso de Direito, criado em julho de 2018, em uma faculdade na Baixada Santista. Para tanto, optou-se pela modalidade de pesquisa-ação, com o objetivo principal de mapear e entender as formas de aprendizagem desse grupo e acompanhá-lo do segundo semestre até a conclusão do curso. Busca-se compreender quais são as perspectivas, frustrações e dificuldades encontradas a cada novo semestre cursado, que poderiam estar limitando potenciais. Busca-se ainda identificar as causas de possiveis evasões ou de um baixo desempenho acadêmico, encontrando, em conjunto com os participantes, metodologias e mecanismos didáticos que possam ser implementados para melhorar a aprendizagem e, consequentemente, elevar resultados práticos desses discentes, com respeito às características individuais de cada um.

Semestralmente os dados coletados são analisados dando suporte para as propostas de trabalho do semestre seguinte. Os relatórios periódicos servem como balizadores para a Direção, Coordenação do curso e Núcleo de Apoio Psicopedagógico, que podem promover ações práticas e efetivas ao alcance de Educação Crítica Inclusiva para todos e todas.

Assim o presente artigo está dividido em duas partes teóricas, com discussão e análise sobre educação inclusiva e avaliações universitárias Interfaces da Educ., Paranaíba, v.11, n.32, p. 106 - 134, 2020 
como forma de exclusão e uma parte prática, representada por um estudo de caso referente à pesquisa-ação que acontece em uma Faculdade de Direito da Baixada Santista, no litoral de São Paulo. A parte prática inclui apresentação de referenciais teóricos, metodologias e resultados obtidos até o presente momento, que servem de parâmetro para ações inclusivas a serem intentadas por outras instituições de Ensino Superior.

Entretanto, antes de tratar da Educação Inclusiva Universitária, considera-se importante contextualizar a Inclusão na perspectiva de Direitos Humanos.

\section{Contextualização da educação inclusiva na perspectiva dos Direitos Humanos}

Da leitura dos textos legais vigentes não é possível se abstrair um conceito uniforme sobre Inclusão ou Educação Inclusiva, sendo tais proposições comumente associadas ao termo Deficiência, levando a um equivocado entendimento de que para haver Inclusão ou Educação Inclusiva seria necessária a pré-existência de uma dificuldade vinculada a esta deficiência.

Ocorre que essa interpretação é restritiva e não alcança todas as pessoas como deseja o objetivo 04 da Agenda 2030 para o Desenvolvimento Sustentável (ONU, 2015).

As pessoas com deficiências foram desde sempre vistas como desacreditadas, e até a década de 1930, por descrenças nas suas possibilidades de desenvolvimento, eram abandonadas ou recolhidas às Santas Casas, demonstrando que a principal preocupação era assistencialista, com a promoção de abrigo e alimentação e com foco na própria deficiência. (JANNUZZI,2004).

No século XX, a concepção da Educação para deficientes passa a ser médico-pedagógica, contando com o envolvimento de médicos e demais profissionais da área da saúde para orientar a ação pedagógica. Centravamse nas causas fisicas, neurológicas e mentais da deficiência e buscavam 
"respostas em teorias de aprendizagem sensorialistas veiculadas na época" (JANNUZZI, 2004, p. 11-12).

Com o avanço da psicologia, houve uma mudança de atuação. A concepção psicopedagógica passou a influenciar a Educação Geral e a Educação voltada às pessoas com deficiências, num movimento denominado Escola Nova, enfatizando "a importância da escola e nela a ênfase nos métodos e nas técnicas de ensino" (JANNUZZI, 2004, p. 12).

Após a segunda guerra mundial, com a Declaração de Direitos Humanos, a Educação tornou-se mais humanizada, o que acabou refletindo na Educação Especial, intitulada Educação de Excepcionais. Tal humanização parte da necessidade da interação entre seres humanos, com respeito à individualidade, às competências e às dificuldades de cada pessoa, levando ao entendimento de que ninguém educa ninguém e tampouco ninguém se educa sozinho. "Os homens se educam entre si, mediatizados pelo mundo" (FREIRE, 2014, p. 6).

Com a ascensão dos Estados Unidos, o capitalismo influenciou na modernização dos institutos educacionais no sentido de aumentar os apelos de organização tecnocrática. (JANNUZZI, 2004).

No Brasil, no entanto, ainda se figurava a Teoria do Capital Humano, apontada como fruto da reorganização ideológica, feita pelo grupo militar responsável pela ditadura de 1964. O objetivo da Educação era formar os alunos para o trabalho, relacionando educação com desenvolvimento da economia. A partir de 1974, a escola passou a ser vista como produtora de recursos humanos, ou seja, mão de obra. Neste contexto, os deficientes eram educados para, tanto quanto possivel, participar de atividades produtivas, garantindo alguma ocupação de tempo e meios de autossubsistência. (JANNUZZI, 2004).

Uma outra teoria, vinda da França, denominada Integração mainstreaming - se apresentou centrada mais no pedagógico, mas não em contradição com a corrente anterior, isto é, supondo o atrelamento da educação ao desenvolvimento, porém, não apenas focada em ocupar ou garantir o sustento de pessoas deficientes, mas sim criar para aqueles que Interfaces da Educ., Paranaíba, v.11, n.32, p. 106 - 134, 2020 
tinham algum retardo mental condições semelhantes às propiciadas para as demais pessoas da sociedade. (JANNUZZI, 2004).

A Integração ou Educação Integradora era, portanto, a recepção de crianças deficientes pela rede regular de ensino, com a realização de adaptações necessárias e buscando mecanismos para que as crianças deficientes se amoldassem àquela escola regular.

O termo Educação Inclusiva (EI) passou a ser internacionalmente utilizado somente a partir de 1994, quando a Declaração de Salamanca ${ }^{1}$ (UNESCO, 1998) prescreveu diretrizes que deveriam ser seguidas pelos Estados-membros da ONU na implementação de seus sistemas Educacionais.

Assim, segundo a Estrutura de Ação em Educação Especial, estabelecida pela Declaração de Salamanca, "as escolas deveriam acomodar todas as crianças independentemente de suas condições físicas, intelectuais, sociais, emocionais, linguísticas ou outras", promovendo uma mudança na perspectiva, segundo a qual não eram mais os alunos e alunas que deveriam se amoldar à escola, mas esta que deveria se adequar para atender as necessidades individuais deles (UNESCO, 1998).

Alguns autores, como Bueno (2008), defendem que erros na tradução original da Declaração de Salamanca datada de 1994 e traduzida pela Unesco novamente em 1998 foram determinantes nas confusões entre Educação Inclusiva, que deveria ser para todas as pessoas indistintamente e Educação Especial, voltada para alunos e alunas com deficiências.

Além disso, a associação das expressões necessidades especiais e necessidades educacionais especiais conduzem ao errôneo entendimento de que todos os alunos ou alunas que se desviam dos padrões de normalidade estariam categorizados como pessoas com necessidades especiais e, portanto, percebidos como pessoas com deficiência (CARVALHO, 2010).

\footnotetext{
1 A Declaração de Salamanca escrita e datada de 1994 não se encontra disponível na internet para consulta. Apenas a versão traduzida pela Unesco em 1998 está disponível.
} 
Independentemente das causas que levaram a Educação Inclusiva a ser confundida com a anterior concepção de Integração, consistente na incorporação da Educação Especial pela Educação Regular, o problema atual que se observa é a inexistência de uma EI de fato, sem o entendimento de que cada ser humano tem suas próprias necessidades específicas, formando uma heterogeneidade que precisa ser trabalhada conjuntamente dentro das salas de aula.

Segundo Mantoan (2003, p. 16), “a inclusão implica uma mudança de perspectiva educacional, pois não atinge apenas alunos com deficiência e os que apresentam dificuldades de aprender, mas todos os demais, para que obtenham sucesso na corrente educativa geral".

Desse modo, a falta de uma Educação Inclusiva pensada como meio de ampliar as condições de matrícula e permanência de todas as pessoas, indistintamente, nas instituições de ensino, com respeito às características, potencialidades e dificuldades individuais de cada ser humano, se torna ainda mais grave quando relacionada às pessoas que estão no Ensino Superior, uma vez que as políticas públicas e ações afirmativas de Inclusão limitam-se aos grupos vulneráveis, formados prioritariamente por crianças deficientes em fase de Educação Básica.

Outro equívoco, observado na prática, é a vinculação do atendimento pedagógico especializado com a apresentação de laudo diagnóstico, mesmo com a Nota Técnica n 04 emitida pelo MEC em 2014 que deixa clara a competência da Instituição de Ensino, e mais especificamente do docente que atua com o aluno ou aluna, para elaborar o Plano de Atendimento Especializado (AEE), com atenção às necessidades específicas de cada um e independente de laudo, que possui caráter clínico e não pedagógico (BRASIL, 2014)

Deve-se ainda considerar que o laudo reflete um diagnóstico universalista, que pode ser interpretado como "um dispositivo catalisador de déficit que acopla numa mesma identidade indivíduos com um mesmo quadro sintomático" (ORRÚ, 2017, p. 1.132/1.134). 
Deste modo, se repete o que é conceituado como anormal, muitas vezes sem qualquer base científico-genética, fundamentado em observação comportamental hipotética, feita de suposições, principalmente quando se refere a transtornos psiquiátricos que ficam adstritos a análise clínica, sendo, portanto, passíveis de erros. (ORRÚ, 2017)

E, uma vez que a diferença é interpretada como algo mal, "busca-se a cura ou paliativos que permitam algum tipo de normalização do indivíduo diagnosticado como anormal" (ORRÚ, 2017, p. 1.134).

Para evitar o equivocado entendimento de que as diferenças, por si só, inferiorizam as pessoas, é necessário utilizar a igualdade como referência. Assim, qualquer pessoa cujas necessidades especificas acarretem prejuízos educacionais poderá receber auxilio para necessidade educacional específica. Do contrário, quando o parâmetro parte da diferença, se elege arbitrariamente características que definiriam a identidade de uma pessoa considerada normal, utilizando essa construção como um padrão para hierarquizar e avaliar todo o alunado. (MANTOAN, 2003)

Outro ponto a ser considerado é a diferença que existe dentro da própria diferença. Cada patologia é passível de afetar a aprendizagem e causar necessidades específicas com características individuais de um sujeito para o outro, o que tornará as dificuldades maiores ou menores mesmo diante diagnósticos similares, impondo uma Inclusão menor, na qual todas as pessoas devem ser concebidas como seres únicos, que apresentam singularidades em seu processo de aprendizagem. (ORRÚ, 2017)

A Inclusão menor rompe com crenças em padrões universais categorizados a partir das diferenças, tornando possivel o acesso e a permanência de todas as pessoas nos espaços de aprendizagem, independentemente de idades ou necessidades específicas, viabilizando a quebra da hierarquização de saberes e estimulando o compartilhamento horizontal de conhecimentos (ORRÚ, 2017).

Categorizar as diferenças evidencia contradições na prática cotidiana. Ainda que um aluno apresente laudo diagnóstico para solicitar ampliação de tempo durante uma avaliação, seja por dislexia, Transtorno do Déficit de Interfaces da Educ., Paranaíba, v.11, n.32, p. 106 - 134, 2020 
Atenção e Hiperatividade (TDAH) ou um dos Transtornos do Espectro Autista (TEA), não há como tabelar referida ampliação temporal com base em cálculos aritméticos individualizados que delimitem a quantidade de tempo concedido a cada pessoa, principalmente se consideradas as características individuais mesmo dentro de determinada categorização. A ampliação de tempo para realização de tarefa não depende da causa que justifique tal dilação, mas sim da necessidade específica para o cumprimento do que foi proposto. É algo que varia de um ser humano para outro.

Do mesmo modo, seria inconcebível negar a um aluno com a perna quebrada o direito de utilizar os meios de acessibilidade, desenvolvidos para cadeirantes em razão de paraplegia, por não se perceber necessidade específica similar, embora parcial e temporária. Ou ainda, sendo literal na interpretação da Lei Brasileira de Inclusão (LBI), não considerar a dificuldade linguística, cultural e emocional de um aluno refugiado, negando-lhe a mesma assistência que legalmente deve ser dispensada a um aluno cego ou surdo com problemas linguísticos e de escrita, mormente porque o refugiado não se enquadraria no conceito de deficiente que "autorizaria" a inclusão, mesmo que com a negativa se estivesse desrespeitando a lei específica de proteção aos refugiados, que também compõem a minoria de vulneráveis.

"Referidas contradições, decorrentes de problemas conceituais, que desrespeitam, inclusive, preceitos constitucionais, acabaram por distorcer o sentido da inclusão escolar". (MANTOAN, 2003, p. 22).

Aplicando a Teoria Social de Goffman (1988), percebemos que a sociedade, ao tentar classificar as pessoas protegidas pela legislação que trata da Inclusão, acabou criando preconcepções que levaram à categorização das pessoas de acordo com sua expectativa de normalidade. Desse modo, estudantes universitários com alguma dificuldade educacional podem ser classificados pejorativamente como estragados ou diminuídos, adquirindo um estigma que deprecia imagem e potencial, tornando-os desacreditados. 
Tais alunos podem, ainda, ter suas próprias necessidades específicas ignoradas por não estarem categorizados entre aqueles que merecem algum tipo de auxilio ou proteção para prosseguir com seus estudos, sendo eles próprios excluídos do sistema educacional.

Nesta linha de raciocínio, uma pessoa cursando o Ensino Superior, para receber apoio educacional deverá se aceitar como anormal, e merecedora de proteção diferenciada, reconhecendo que o fracasso é esperado diante de suas limitações, além de correr o risco de ser mal recepcionada por colegas de turma e professores em razão de discriminações infundadas, ou fundadas no próprio desconhecimento sobre as diferenças do outro. (GOFFMAN, 1988).

A incerteza no que diz respeito à forma como será recepcionado caso admita dificuldades, pode amedrontar o aluno ou aluna, fazendo-o omitir necessidades específicas. Do mesmo modo, o professor ou professora, ao não saber como lidar com a necessidade específica desse aluno ou aluna, pode permitir que inseguranças e incertezas impeçam uma ação positiva, no sentido de fazer a acolhida que precisam. Mas essa mesma incerteza pode motivar alunos e professores a agirem. (PIRES \& PIRES, 2013)

Compete a cada docente aceitar o desafio de acolher os alunos como são, sem a pretensão de corrigir as necessidades específicas, do mesmo modo que compete a cada aluno conhecer suas próprias necessidades específicas e aceitá-las como parte de si, e não como um obstáculo que impeça a continuidade de seu progresso.

Há correlação entre desempenho educacional e comportamento dos alunos deficientes no processo de ensino-aprendizagem. A forma como o aluno é recepcionado em sala de aula por colegas e professores pode favorecer relações interpessoais, que ocorrem de forma mais colaborativa do que competitiva e ultrapassam os muros da instituição de ensino. Para os docentes, a experiência de ter alunos com deficiência não demonstra efeitos sobre as atitudes sociais dos mesmos em relação à inclusão. Tal percepção é associada com a possivel natureza da relação dos professores com seus alunos sem a criação de relações interpessoais específicas, que, caso Interfaces da Educ., Paranaiba, v.11, n.32, p. 106 - 134, 2020 
existissem, possibilitariam a compreensão e o eventual equacionamento das dificuldades que algum destes alunos pudessem vir a apresentar, admitindo, inclusive, a possibilidade daqueles docentes sequer terem conhecimento sobre alunos deficientes em suas turmas, caso as deficiências não sejam perceptiveis. (CHAHINI, 2016)

Ademais, é preciso refletir que a pessoa deficiente já transitou pela Educação Básica, cujo meio propiciou oportunidades de reconhecer dificuldades e encontrar caminhos indiretos para compensação, pela própria necessidade de comunicação que funciona como uma autoignição do desenvolvimento cultural (VIGOTSKI, 2011).

Isso implica dizer que os deficientes físicos, visuais ou auditivos, ao chegarem na universidade, provavelmente já encontraram meios mecânicos, ou formas compensatórias para adaptar suas dificuldades. Com o conhecimento das suas necessidades específicas limitadoras, fica mais fácil para o adolescente ou adulto indicar ao docente o auxílio que precisa para melhor apreensão do conteúdo. O mesmo não ocorre com uma criança da Educação Básica que ainda está aprendendo a lidar com suas necessidades específicas.

Ainda há o agravante vivido por pessoas com deficiências no contexto de extrema pobreza, violências familiares e ações indiretas da sociedade que atuam a longo prazo, como a morte de membros de suas famílias, ou se assentam muitas vezes na própria desigualdade estrutural e em processos sociais. Nessas circunstâncias, a Educação também se apresenta como um meio para superar a pobreza e como via necessária para a Inclusão social, assumindo um importante papel na promoção de ideais relacionados com a paz, a liberdade e a justiça (BARNES, 2010).

\section{Avaliações como forma de exclusão}

Estar em uma Instituição de Ensino Superior, consideradas as dificuldades para tal, já representa uma vitória para pessoas que apresentam necessidades específicas, pois simboliza a superação de inúmeros obstáculos já enfrentados. 
Percebe-se que independentemente do objetivo dessas pessoas, todas serão avaliadas por meio de provas, não apenas pela Instituição que escolheram para cursar, mas também, por órgãos que garantem o ingresso em carreiras públicas, ou pela Ordem dos Advogados do Brasil (OAB), caso optem pelo exercício da advocacia, transferindo, consequentemente, para a Instituição de Ensino Superior (IES) a responsabilidade de lhes preparar para tal, em uma tarefa extremamente complexa.

Em relação às avaliações, contudo, é preciso observar que nem sempre a metodologia e a didática do professor são compativeis com o tipo de avaliação aplicada, o que impede que o resultado obtido reflita a real aprendizagem dos alunos e alunas quanto a determinados conteúdos. Conforme Saul (2008, p. 19), existem diversas modalidades de avaliação: "avaliação da aprendizagem ou avaliação do rendimento escolar ou, ainda, avaliação do aluno".

As instituições de ensino definem uma forma de avaliação sem respeitar o processo de aprendizagem de cada aluno, que é individual, tendo cada um seu próprio tempo, forma e estratégia de aprendizagem, e a partir destas avaliações promove julgamentos generalizados (ROMANOVSKI; WACHOWICZ, 2006).

Além disso, as instituições são cobradas por órgãos como o Ministério da Educação e Cultura (MEC) quanto ao aprendizado dos alunos, submetendo-os a processos avaliativos uniformes, como o Exame Nacional de Desempenho dos Estudantes (Enade), que não respeitam a individualidade dos alunos tampouco a autonomia institucional e de professores quanto à metodologia e didática utilizadas para esse processo de ensino-aprendizagem, especialmente porque a prova Enade, por exemplo, é uma avaliação formativa que busca o conhecimento global e as disciplinas do Direito têm seu conteúdo ministrado de forma fragmentada.

Assim, cria-se um paradoxo educacional. Os alunos, em algum momento, serão testados por meio de avaliações que exigirão um conhecimento padronizado e teórico, enquanto o mercado de trabalho cada 
vez mais demanda profissionais criativos e com capacidade de encontrar soluções para problemas que não existiam no passado.

Diante desse dilema, as faculdades e universidades, com o agravante de suas cargas horárias reduzidas, acabam optando entre "treinar" alunos para provas objetivas e alternativas como Enade, Ordem dos Advogados do Brasil (OAB) e concursos públicos ou ensiná-los por meio de reflexão, raciocínio e argumentação, que os levarão a verdadeiros impasses na hora de responder questões alternativas eivadas de "pegadinhas" para quem não "decorou" determinado conteúdo, transformando as provas avaliativas nos próprios obstáculos universitários.

Os resultados avaliativos dos alunos e alunas deveriam ser analisados seguindo o processo ensino-aprendizagem, no marco da avaliação emancipatória, proposto por Saul (2008, p.23), que busca a participação discente para compreender as reais dificuldades e, ao mesmo tempo, favorece o autoconhecimento sobre as próprias características de aprendizagem, contribuindo para que os alunos se tornem sujeitos do seu processo de aprendizado.

$\mathrm{Na}$ avaliação emancipatória é preciso utilizar mecanismos que destaquem potencialidades e habilidades dos alunos e alunas e não os que apenas evidenciam dificuldades, estabelecendo-se uma relação pedagógica democrática entre educador e educando, priorizando assim, os aspectos qualitativos do desenvolvimento dos alunos aos resultados quantitativos de seus desempenhos representados por notas (SAUL, 2008)

Portanto, a mudança de perspectiva educacional para o alcance da Educação Inclusiva Universitária também implica a necessidade de revisão dos métodos avaliativos, que podem ser incongruentes com as metodologias e com as próprias individualidades, necessidades específicas e formas de aprendizagem de cada pessoa.

Por fim, é preciso considerar que as deficiências nem sempre são dos alunos, mas do próprio ensino ou da forma como foi ministrado. Os processos avaliativos estão empenhados em descobrir o quanto o aluno aprendeu, e não como as universidades ensinaram. O resultado apresenta Interfaces da Educ., Paranaíba, v.11, n.32, p. 106 - 134, 2020 
penalizações como repetência, evasão, discriminação, exclusão, e impede uma Inclusão total e irrestrita. (MANTOAN, 2003)

\section{Metodologia: pesquisa-ação para entendimento da individualização dos sujeitos}

Como inovar o curso de Direito para que seja inclusivo, de forma total e irrestrita?

Seguindo os ensinamentos de Mantoan (2003, p.31), acredita-se que "inovar não tem necessariamente o sentido do inusitado. As grandes inovações são, muitas vezes, a concretização do óbvio, do simples, do que é possivel fazer, mas que precisa ser desvelado, para que possa ser compreendido por todos".

Sem desmerecer estudos científicos que sugerem formas específicas para trabalhar com cada uma das deficiências categorizadas, reconhece-se a relevância de o docente conhecer cada uma das possiveis características comportamentais e necessidades específicas de alunos com deficiências mais severas para facilitar o processo de elaboração de aulas, com opção por metodologias de mais conectividade, acredita-se que tais escolhas deverão necessariamente ser aplicadas para todos os membros do grupo conjuntamente, sem diferenciação da forma de aula apresentada para um ou outro aluno, como forma de promover a inclusão buscada.

Assim, este trabalho de pesquisa-ação teve como base as perspectivas propostas por Franco (2016) para formação do próprio professor/professora, mas que aqui estendemos aos pesquisadores que enquanto pesquisam atuam como mediadores educacionais objetivando produzir a troca de conhecimento entre todos os membros do grupo, de forma a melhor compreender as práticas que vêm sendo aplicadas no curso de Direito.

A intencionalidade é trabalhar concomitantemente com a pesquisa e a ação, sendo ao mesmo tempo pesquisadora e prática, "com a finalidade de transformação social". (FRANCO, 2012, p.181).

Dentro desta proposta, o que se pretende é construir um universo cultural, com a participação coletiva do grupo analisado e permitindo a Interfaces da Educ., Paranaíba, v.11, n.32, p. 106 - 134, 2020 
contribuição de todos, o que não se confunde com "organizar textos ou aulas para ‘aplicar' nos participantes!” (FRANCO, 2016, p. 516).

Com esse ideal em mente, os 74 alunos e alunas, matriculados em março de 2019 no segundo semestre da primeira turma do curso de Direito de uma faculdade da Baixada Santista, foram convidados a participar de um grupo que se reuniria semanalmente para conversas sobre o curso, as aulas, suas expectativas e dificuldades. A pesquisadora atuou como mediadora destas conversas, visando aproximar os participantes e incentivá-los a perceber que cada um possuía características que os individualizava dos demais.

Enquanto a pesquisadora atuava diretamente com o grupo, em uma metodologia analítica - observacional - participativa, trabalhava o autoconhecimento do grupo e, em conjunto com os mesmos tentava identificar as necessidades específicas e as dificuldades de aprendizagem de cada um, para, posteriormente, trabalhar com os alunos integrantes da equipe os conteúdos aprendidos no semestre, a partir do material dado pelos professores em aula.

Todos os participantes foram informados que poderiam deixar de ir aos encontros do grupo quando quisessem, porém, três faltas às reuniões seriam interpretadas como desistência de suas participações não mais podendo retornar ao grupo durante o semestre.

Para entender a forma como cada um destes alunos e alunas aprendiam, objetivando escolher metodologias de ensino que fossem mais eficazes para ampliar o conhecimento sobre os conteúdos ministrados, aplicou-se o Learning Style Inventory (LSI), criado por David A. Kolb em $1971^{2}$ e que analisa os estilos de aprendizagens experienciais, com base nas potencialidades e formas de ações individuais.

Por meio de um processo de autoanálise, os participantes se reconheceram como Acomodadores, Divergentes, Convergentes e

\footnotetext{
${ }^{2}$ A empresa Experience Basead Learning Systems, LCC, presidida por Alice Kolb, já anunciou o LSI 4.0, mostrando que é possível definir outros tipos de estilos de aprendizagem além do estilo dominante, evidenciando que mesmo as potencialidades humanas não são uniformes e nem podem ser categorizadas.
}

Interfaces da Educ., Paranaíba, v.11, n.32, p. 106 - 134, 2020 
Assimiladores. Devido à preferência por situações práticas, Acomodadores Divergentes, ou por teorias e conceitos, caso dos Convergentes e Assimiladores. Acomodadores e Convergentes que preferem agir, tomando rápidas decisões e Divergentes e Assimiladores preferem pensar, utilizando mais a lógica e o raciocínio indutivo (KOLB, 1994).

Na primeira reunião, compareceram 26 alunos, dos 74 convidados para conhecerem a proposta, na segunda reunião retornaram somente 18 alunos e destes apenas 12 permaneceram assiduos, concluindo a primeira etapa da pesquisa no início de julho de 2019.

Em agosto de 2019, com o retorno das reuniões do grupo de pesquisa, o número de alunos matriculados na Instituição foi reduzido em aproximadamente $15 \%$, mas o grupo da pesquisa recebeu novos participantes, o que elevou o número de 12 para 16, contando com uma baixa referente à aluna que trancou a matrícula.

No início de 2020 o número de matriculados no terceiro semestre do curso de Direito totalizava 52 alunos, e o grupo de pesquisa, mesmo com 4 baixas, foi ampliado para 25 participantes. Também em 2020, o período dos encontros foi ampliado, ocupando o dia da semana reservado para a Educação a Distância (EAD).

Nas reuniões que antecediam as avaliações, eram realizadas rodas de conversas sobre os conteúdos estudados com uma proposta freireana, na qual "o diálogo implica responsabilidade, direcionamento, determinação, disciplina, objetivos [...]. Significando uma tensão permanente entre a liberdade e autoridade". (FREIRE, 1997, p. 127)

Após as provas, os participantes foram consultados sobre suas percepções em relação ao semestre e sobre os métodos avaliativos. Os dados obtidos a cada semestre geravam relatórios e, a partir deles, novas estratégias de intervenção eram pensadas para o semestre seguinte.

Até a presente data, quando as reuniões vêm ocorrendo de forma virtual em razão do COVID-19 que interrompeu as aulas presenciais, os pesquisadores avaliaram a importância da pesquisa, e os resultados alcançados, culminando na elaboração deste artigo. 


\section{Resultados: as diferentes formas de aprendizagem}

A cada semestre os alunos que ingressam no grupo de pesquisa respondem um questionário semiestruturado com informações básicas como idade, onde cursaram o ensino médio, se é a primeira graduação, se possuem bolsa, razões que os levaram a escolher o curso de Direito e a Instituição de ensino em que estão. As respostas preliminares confirmam, em parte, o fator socioeconômico como um dos maiores obstáculos ao Ensino Universitário.

Das 30 pessoas que já compuseram o grupo de análise, 50\% estão na faixa etária dos 30/39 anos; 25\%, na faixa etária dos 40/49 anos; 10\%, na faixa etária dos acima de 50 anos e apenas 5\%, na faixa etária dos 20/30 anos. A pesquisa demonstra uma média etária elevada se comparada com a idade dos alunos que concluem o ensino médio e prestam vestibular na sequência. Além disso, para 90\% dos participantes esta é a primeira oportunidade de cursar uma graduação. Dentre eles, apenas 12 declararam possuir formação técnica. Embora a faculdade de Direito seja particular, os participantes da pesquisa declararam ter cursado o ensino médio em escola pública. Apenas 8 possuem bolsa pelo PROUNI, sendo que um deles declarou receber apenas o percentual de 50\%.

A escolha do curso de Direito foi associada a questões como vocação, gosto, interesse, amor, propósito, intenção de ajudar ao próximo e interesse por conhecer a lei e os direitos. Um dos participantes afirmou que a escolha teve relação com oportunidade e conhecimento prévio de direito eleitoral mesmo preferindo a área de exatas, e outro se referiu à escolha por exclusão, uma vez que não se adaptou à área de exatas que trabalhou anteriormente.

As respostas indicam que as escolhas dos cursos de graduação, especialmente quando feitas por pessoas com mais maturidade, estão geralmente vinculadas com suas aptidões e interesses, o que é um aspecto facilitador para a aprendizagem.

Embora 90\% dos integrantes tenham feito referência ao valor da mensalidade, possibilidade de bolsa pelo PROUNI e localização do Interfaces da Educ., Paranaíba, v.11, n.32, p. 106 - 134, 2020 
estabelecimento de ensino como fatores determinantes para a escolha da Instituição, nas respostas sobre dificuldades gerais ou específicas nenhum dos participantes fez menção à dificuldade econômica para ingresso ou manutenção no curso.

No primeiro semestre da pesquisa, 09 das 12 pessoas participantes focaram em problemas de relacionamentos interpessoais e de comunicação, 02 fizeram referência à falta ou dificuldade na gestão de tempo e apenas 01 relatou dificuldade cognitiva relacionada com a matéria do curso.

Apesar de todos os participantes, de todos os semestres, terem cursado o ensino médio em escola pública, $90 \%$ deles não associam suas dificuldades na graduação com a formação de base. 30\% afirmam que tais dificuldades estão relacionadas mais com a lacuna de tempo em que ficaram sem estudar, embora se constate, na escrita de alguns, pequenas defasagens associadas ao ensino fundamental.

Nenhum participante declarou deficiências físicas, mentais ou sensoriais. $83,4 \%$ negaram ter necessidades específicas ou dificuldades de aprendizagem relacionada com fatores cognitivos. Apenas 02 relataram ter dificuldades educacionais, 01 fez referência à matéria de direito penal e outro declarou ter muita dificuldade de aprender apenas ouvindo sem um apoio visual para leitura, relatando ainda se confundir com frases longas, especialmente relacionadas ao direito civil e constitucional.

De modo informal, alguns participantes relataram características que poderiam ser associadas a Transtornos de Ansiedade, ou Transtorno do Déficit de Atenção e Hiperatividade, e, um deles, admitiu tomar a medicação Ritalina (indicada para pessoas com TDAH), sem, no entanto, encarar tais condições fisiológicas como deficiências.

Como a concepção de inclusão aplicada pelos pesquisadores independe de categorizações em relação à deficiência, o dado obtido apenas serve para comprovar que realmente muitos alunos no curso universitário possuem necessidades específicas, mas sequer as reconhecem e, portanto, tal informação, não chega ao docente. 
A pesquisa constatou ainda que os alunos e alunas não reconhecem suas dificuldades de aprendizagem, alguns medem as dificuldades pelas notas obtidas, ou seja, alunos com boas notas afirmam não ter dificuldades de aprendizagem, e alunos com notas mais baixas apontam que suas dificuldades estão relacionadas com aquelas matérias em que seu desempenho não foi tão elevado durante as avaliações.

Porém, quando as reuniões tratavam de assuntos específicos ministrados nas aulas mais de $80 \%$ dos participantes demonstravam não ter compreendido inteiramente e a maioria dos presentes encontrava dificuldade de citar exemplos práticos sobre os conteúdos apreendidos que fossem diferentes daqueles exemplos citados pelo professor ou professora em sala de aula, levando a suposição de que alguns não se sentiam confortáveis para declararem suas dificuldades, por medo de exposição.

Considerando a diversidade humana, e concebendo que cada pessoa aprende de uma forma diferente, constatou-se ser praticamente impossivel a criação de um único método educacional que atenda a todos os alunos e alunas, sendo impossivel pensar em Educação Inclusiva, especialmente em nível Universitário, sem considerar tais individualidades humanas.

Dentre os 12 participantes do primeiro semestre da pesquisa 06 tiveram seus resultados do LSI localizados no quadrante superior esquerdo, se identificando como Acomodadores (que aprendem fazendo, colocando em prática, preferindo tentativas e erros do que longas reflexões) e os outros 06 tiveram seus resultados localizados exatamente no quadrante oposto, na parte inferior direita do gráfico, se identificando como Assimiladores (que aprendem com conceitos e teorias, preferindo longas reflexões com análise das situações sobre diversos ângulos).

Portanto, a análise de conteúdos e didáticas aplicadas a cada grupo de discentes deve levar em conta as características personalizadas destes alunos e alunas, partindo assim da conscientização dos próprios alunos sobre suas formas de aprendizagem e auxiliando os mesmos para que encontrem maneiras de melhorar a sua relação interpessoal com cada professor/professora (respeitado o método educacional escolhido por estes). Interfaces da Educ., Paranaíba, v.11, n.32, p. 106 - 134, 2020 
Ao melhorar o autoconhecimento dos alunos sobre suas próprias características pessoais e a forma como seu cérebro processa o conhecimento, os participantes melhoraram as formas de interagirem com os professores de cada matéria, obtendo respostas e direcionamentos necessários para ampliação de suas aprendizagens e conhecimentos.

A faculdade onde o curso de direito é ministrado fez a opção pedagógica de trabalhar uma única matéria por dia da semana, dando maior tempo ao docente para desenvolver os conteúdos com os alunos sem que haja excesso de informação divergente ou confusões com outras disciplinas, sendo um dia da semana destinado à EAD, e, neste semestre, ocupado pelos encontros com o grupo de pesquisa. Porém, a maioria dos participantes relatou que as aulas acabavam parecendo extensas e cansativas, dando a sensação de que o tempo não estaria sendo bem aproveitado, e de que as conversas sobre a matéria seriam apenas para preenchimento da carga horária.

Por outro lado, outros participantes reclamavam também de aulas estruturadas e que se prendiam a divisão do tempo, com uso de power point para delimitação de conteúdo, solicitando exatamente as conversas menos formais e mais abrangentes quanto ao conteúdo.

Comparando as reclamações dos participantes com as formas de aprendizagem de cada um deles se tornou fácil constatar que os alunos que se reconheciam como Acomodadores não conseguiam prestar atenção em aulas expositivas tão longas e sentiam falta de exercícios práticos, enquanto os alunos que se reconheciam como Assimiladores achavam que as aulas que aplicavam alguma forma de metodologia ativa padeciam de conteúdo e discussão teórica.

Confirmando a diferença dos estilos de aprendizagem, 06 participantes apresentavam reclamações quanto a forma de ensino de um determinado professor, que ministrava aulas extremamente teóricas com apoio em exemplos repetitivos, enquanto outros 06 reclamavam da didática utilizada por uma professora, que se prendia às apresentações de power point sem exemplos práticos e sem oportunidades para aprenderem fazendo. 
Essa constatação coaduna com o pensamento de MANTOAN (2003), que afirma a desnecessidade de práticas especificas para cada deficiência e/ou dificuldade de aprendizagem, pois cada aluno ou aluna vai aprender no seu tempo e dentro de seus limites, cabendo ao docente aceitar esses limites e explorar as potencialidades de cada um.

Pouco após escutá-los e trabalhar com os participantes o autoconhecimento e como cérebro e raciocinio funcionavam, dando-lhes encaminhamento para formularem perguntas ao docente que fossem eficazmente preencher a sua lacuna de conhecimento, eles reportaram uma alteração na metodologia adotada pelo professor e uma melhora na qualidade de aprendizado, alterando inclusive a conceituação e melhorando positivamente a percepção dos alunos e alunas em relação a determinado professor.

Outra dificuldade apresentada se referia à linguagem técnica formal muito utilizada nos cursos de Direito, tornando o entendimento das explicações e dos próprios enunciados dos exercícios complexos e de difícil compreensão para alguns participantes.

Porém, quando a pesquisadora seguiu os ensinamentos de FREIRE (2017), e contextualizou os conteúdos dentro da realidade dos participantes, apresentando explicações com uma linguagem mais coloquial, a compreensão dos participantes elevou-se.

No segundo semestre da pesquisa, quando as aulas regulares já estavam sendo ministradas por professores contratados para atender a demanda do curso e que apresentavam uma didática mais adequada ao grupo, todos os participantes relataram maior facilidade de compreensão, e, embora o conteúdo fosse mais denso e a matéria mais extensa, sentiam-se mais à vontade para interceder durante as aulas com perguntas.

Apesar de afirmarem que os docentes interagiam mais com a classe e que tinham mais facilidade na explanação de conteúdos, o resultado quantitativo das provas aplicadas pelos professores em outubro de 2019 foi decepcionante para a quase totalidade dos participantes, demonstrando que talvez a forma avaliativa não tenha sido escolhida de acordo com a didática. 
Em relação a uma das matérias, os participantes relacionaram o baixo desempenho com a ausência de material didático que não era fornecido pelo docente. Para $50 \%$ dos participantes, as rodas de conversa fizeram falta na preparação para a primeira prova do segundo semestre, pois, embora reconhecessem a extrema capacidade e conhecimento do professor, não sabiam como se preparar para a avaliação, transparecendo que uma das maiores dificuldades em nível universitário é encontrar um método de estudo adequado para a forma de aprendizagem.

Como as provas Institucionais seguem o formato de questões alternativas, os alunos se apoiam em questionários para auxiliar na memorização, sem preocupação com o entendimento do conteúdo. Como tais exercícios não foram fornecidos, os alunos não souberam estudar.

Antes da realização da POI (Prova Institucional), o professor referido acima forneceu questionários para direcionamento dos estudos e os participantes afirmaram que essa diretriz auxiliou a orientação de seus estudos, melhorando o desempenho quantitativo em relação à primeira avaliação da matéria. As rodas de conversas também foram apontadas pela unanimidade dos participantes como um valioso auxilio para melhoria de aprendizagem e autoconhecimento quanto sua forma de apreensão de conhecimentos.

Dentro da pesquisa-ação proposta, todos os alunos e alunas participantes tiveram melhora de aprendizagem em relação ao primeiro semestre, devido ao autoconhecimento. Nenhum dos participantes do primeiro e segundo semestre ficou em exame, obtendo a média necessária com as avaliações regulares e demonstrando maior entendimento dos conteúdos.

Por melhoria de aprendizagem, com respeito às diversidades humanas, observou-se que os participantes aperfeiçoaram a argumentação e melhoraram suas respostas, que se apresentam mais objetivas e claras. (ROMANOVSKI; WACHOWICZ, 2006)

Com relação ao curso, as únicas reclamações que restaram ao final do segundo semestre de pesquisa, e terceiro do curso, foi quanto à extensão do Interfaces da Educ., Paranaíba, v.11, n.32, p. 106 - 134, 2020 
conteúdo que acaba sendo apenas pincelado em alguns pontos em razão dô curto espaço de tempo, com matérias importantes sem o aprofundamento merecido.

Neste ano de 2020, os participantes e a pesquisadora optaram por trabalhar em grupo com casos práticos, aplicando os conhecimentos teóricos recebidos nas aulas para verificar o quanto a antecipação da prática jurídica, que ocorre regularmente apenas no oitavo semestre, pode melhorar a compreensão dos conteúdos já apreendidos.

Enquanto este artigo estava sendo escrito um outro desafio se apresentou ao grupo. Em razão do COVID-19, pandemia que obrigou o fechamento da faculdade, as reuniões do grupo passaram a ser via Plataforma zoom. Porém, dos 25 integrantes atuais, apenas 20 conseguem participar e 05 têm dificuldades devido à falta de acesso à internet ou à plataforma, demonstrando mais uma vez as limitações impostas por razões socioeconômicas.

Tais dificuldades também haviam sido relatadas em relação às matérias ministradas em EAD, pois, além da barreira tecnológica, a ausência de um professor para debater e sanar dúvidas afetou diretamente a cognição do conteúdo trabalhado. Aos pesquisadores, neste momento atual, resta o desafio de encontrar maneiras de trabalhar a Educação Inclusiva através do mundo virtual.

\section{Considerações finais}

Este artigo buscou promover uma reflexão sobre a Educação Inclusiva na perspectiva de Direitos Humanos, acreditando que sua efetiva implementação depende de uma mudança de perspectiva, ao aceitar que a categorização dos seres humanos pautada por suas deficiências é a principal razão de estigmatização e exclusão no âmbito universitário.

Os fatores que obstaculizam o acesso e permanência no Ensino Superior não se limitam às deficiências físicas, mentais e sensórias, como positivado na legislação vigente. Fatores culturais, psicológicos, sociais e econômicos são grandes responsáveis pelas dificuldades apresentadas na Interfaces da Educ., Paranaíba, v.11, n.32, p. 106 - 134, 2020 
Educação Universitária, e não podem ser ignorados, sob pena de ampliar o número de vulneráveis sem acesso à Educação.

Quando se considera a diversidade humana, com a diferença presente dentro da própria diferença, é preciso aceitar a impossibilidade de categorizações sem o cometimento de injustiça contra aqueles que forem privados do acesso e permanência no Ensino Superior.

E, exatamente por acreditar que cada ser humano tem suas próprias necessidades específicas, nos aproximamos do pensamento de Mantoan (2003), ao afirmar que somos incapazes de antever as dificuldades e as facilidades que cada aluno encontrará em seu percurso educacional, pois o desenrolar dentro de uma sala de aula, seja no ensino básico ou no curso universitário, vai depender exclusivamente da forma como cada aluno ou aluna interage com o professor e o grupo, pelo que propostas padronizadas de aulas acabam sendo excludentes.

Pesquisas científicas já demonstraram que o acolhimento e a empatia entre os alunos e seus pares e professores facilita o processo de Inclusão. Permanência ou evasão escolar estão mais relacionadas com a percepção do aluno com sua aprendizagem do que com os obstáculos enfrentados. Assim, compreende-se que mais eficaz do que tentar justificar cada ação ou dificuldade humana, buscando as suas causas, é se abrir a todas as possibilidades, aprendendo dia após dia com cada aluno que cruzar a sala de aula.

A não categorização também pressupõe o não julgamento, e pensar sobre julgamento implica pensar avaliação, que se reflete como outro grande objeto de exclusão, visto que nem sempre é o meio mais adequado de avaliar o aprendizado, destacando muito mais as dificuldades do que o conteúdo de fato aprendido.

Por meio da pesquisa-ação, constatou-se que os alunos universitários não se declaram como deficientes nem reconhecem necessidades específicas ou dificuldades de aprendizagem, ainda que elas estejam presentes.

A aprendizagem é mensurada pelos alunos de acordo com as notas. Acreditam que compreenderam melhor o conteúdo de matérias que Interfaces da Educ., Paranaíba, v.11, n.32, p. 106 - 134, 2020 
numericamente obtiveram melhor resultado, sem ponderar sobre o real entendimento desses conteúdos ou considerar que o estilo de prova pode não ser condizente com a metodologia do professor ou com sua forma de estudo.

E como as dificuldades que cada discente apresenta não são percebidas naturalmente por eles, não conseguem pedir auxílio e muitas vezes responsabilizam o professor pelo baixo rendimento ou pouco entendimento das matérias ministradas.

Ao trabalhar o autoconhecimento, ensinando técnicas para que os próprios alunos suprissem lacunas da aprendizagem, bem como ao intervir com os alunos por meio de metodologias ativas e exemplos cotidianos, observou-se uma melhoria não apenas na aprendizagem mas na própria interação docente $\mathrm{x}$ discente, comprovando a teoria de Romanovski e Wachowicz (2006), que afirmam que a participação dos alunos e alunas examinando os aspectos que interferem em sua cognição, amplia sua autonomia e qualidade de produção, melhorando a produção de conhecimentos.

Portanto, é fundamental a formação de professores livres de padrões pré-estabelecidos de aulas, que trabalhem com diferentes metodologias de ensino, equilibrando aulas teóricas e práticas, por meio de aulas cooperativas, considerando a individualidade dos discentes e trabalhando o autoconhecimento com eles. Desse modo, promove-se o que entendemos por Educação Inclusiva de fato e de direito, que atende as necessidades específicas dos alunos e alunas, preparando-os não apenas para se sobressaírem nos testes a que forem submetidos, mas principalmente formando cidadãos críticos por meio de uma Educação de qualidade como objetiva a Agenda 2030, através do Objetivo 04 para o desenvolvimento sustentável.

\section{Referências}

BARNES, C. Discapacidad, política y pobreza en el contexto del "Mundo Mayoritario”. Política y Sociedad, Vol. 47, Núm. 1, p. 11-25, 2010. Disponível em: 
https://revistas.ucm.es/index.php/POSO/article/view/POSO1010130011A /21663. Acesso em: 08 abr. 2020.

BRASIL. Ministério da Educação. Nota Técnica $n^{o}$ 04/2014/MEC/SECADI/DPEE de 23 de janeiro de 2014. Orientação quanto a documentos comprobatórios de alunos com deficiência, transtornos globais do desenvolvimento e altas habilidades/superdotação no Censo Escolar. [Online]. 2014b. Disponivel em:

http:/ / portal.mec.gov.br/index.php?option=com_docman\& view=download\&alias $=15898-$ nott04-secadi-dpee23012014\&category_slug=julho-2014-pdf\&Itemid=30192. Acesso em: 19 jan. 2019.

BUENO, J. G. S. As políticas de inclusão escolar: uma prerrogativa da Educação Especial? In: BUENO, J. G. S; MENDES, G. M. L; Santos, R. A (Orgs.). Deficiência e escolarização: novas perspectivas de análise. Araraquara: Junqueira e Marin; Brasília: CAPES, 2008. p. 43-63.

CARVALHO, R. E. Removendo as Barreiras para a aprendizagem: educação inclusiva. 9. ed. Porto Alegre: Mediação, 2010.

CHAHINI, T. H. C. Atitudes Sociais em relação à inclusão de alunos (as) com deficiência na Educação Superior. Interfaces da Educ., Paranaíba, v. 7, n. 19, p. 314-328, 2016. Disponível em:

https:// periodicosonline.uems.br/index.php/interfaces/article/view/837/9 66. Acesso em: 12. abr.2020.

FRANCO, M. A. S. Pesquisa Ação - Pedagógica: Práticas de Empoderamento e Participação. EDT - Educação Temática Digital. Campinas, SP. V.18, n.2, p. 511-530, abr/jun 2016. ISSN 1676-2592. Disponivel em:

https://periodicos.sbu.unicamp.br/ojs/index.php/etd/article/view/863750 7/13331. Acesso em: 01 nov. 2018. 
FRANCO, M. A. S. Pedagogia e Prática Docente. São Paulo: Cortez, 1997. FREIRE, P. Pedagogia da autonomia. São Paulo: Cortez, 1997.

FREIRE, P. O Papel da Educação na Humanização. 2014. Resumo de palestras realizadas em 05-1967, em Santiago, sob o patrocínio da OEA, do Governo do Chile e da Universidade do Chile). Publicado originalmente em Revista Paz e Terra. São Paulo, N. 9, p.123-132, out. 1969. Disponível em: http:/ / www.rcdh.es.gov.br/sites / default/files/Freire, \%20Paulo\%201969\%2 OPapel\%20da\%20educacao\%20na\%20humanizacao.pdf. Acesso em: 19 fev.2020.

FREIRE, P. A importância do ato de ler em três artigos que se completam. 51 . ed. São Paulo: Cortez, 2017.

GOFFMAN, E. Estigma: notas sobre a manipulação da identidade deteriorada. Rio de Janeiro: LTC, 1988.

JANNUZZI, G. Algumas concepções de educação do deficiente. Rev. Bras. Cienc. Esporte, Campinas, v. 25, n. 3, p. 9-25, maio 2004. Disponivel em: http://www.oldarchive.rbceonline.org.br/index.php/RBCE/article/viewFile/ 235/237. Acesso em: 05 abr. 2020.

KOLB, D. A. Experiential Learning: Experience as The Source of Learning and Development. Prentice Hall, Inc., Englewoods Cliffs, New Jersey, 1994. Disponivel em:

http:/ / www.learningfromexperience.com/images / uploads / process-of-of experiencial-learning.pdf. Acesso em: 28 jul. 2019.

MANTOAN, M. T. E. Inclusão Escolar - O que é? Por quê? Como fazer? São Paulo: Moderna, 2003. 
ORGANIZAÇÃO DAS NAÇÕES UNIDAS (ONU). Agenda 2030. Traduzido pelo Centro de Informação das Nações Unidas para o Brasil (UNIC Rio). On-line, 2015. Disponivel em: https://nacoesunidas.org/pos2015/agenda2030/. Acesso em: 04 abr. 2017.

ORRÚ, S. E. O re-inventar da inclusão: os desafios da diferença no processo de ensinar e aprender. Petrópolis, RJ: Vozes, 2017.

PIRES, J.; PIRES, G. N. da L. Uma introdução à ética do ser humano. In: MELO, F. R. L. V. Inclusão no ensino superior: Docência e Necessidades Educacionais Especiais. Editora da EDUFRN, Natal, RN, 2013, p. 25-45.

ROMANOWSKI, J. P.; WACHOWICZ, L. A. Avaliação formativa no ensino superior: que resistências manifestam os professores e os alunos? In ANASTASIOU, L. G. C.; ALVES, L. P. (Orgs.). Processos de ensinagem na universidade: pressupostos para as estratégias de trabalho em aula. 6. ed. Joinvile-SC: UNIVILLE, 2006. p. 121-139.

SAUL, A M. Referenciais Freireanos para Prática da Avaliação. Revista de Educação PUC-Campinas, n. 25, p. 17-24, novembro 2008. Disponível em: http://periodicos.puccampinas.edu.br/seer/index.php/reveducacao/article/view/90/79. Acesso em: 10 mai. 2019.

UNESCO. Declaração de Salamanca sobre Princípios, Politica e Práticas na Área das Necessidades Educativas Especiais. Salamanca/Espanha, 1998 [1994]. Código: BR/1998/PI/H/7. Disponível em:

https://unesdoc.unesco.org/ark:/48223/pf0000139394. Acesso em: 04 abr. 2017. 
VIGOTSKI, L. S. A defectologia e o estudo do desenvolvimento e da educação da criança anormal. Educação e Pesquisa, São Paulo, v. 37, n. 4, p. 861 870, dez. 2011. Disponível em:

http://www.scielo.br/scielo.php?script=sci_arttext\&pid=S151797022011000400012\&lng=es\&nrm=iso. Acesso em: 06 abr. 2020. 